\title{
CHARACTERIZATION OF SPONGE-GOURD RESIDUE PRETREATED BY MECHANICAL DISC REFINING
}

\author{
THIAGO R. CORREIA, JESSICA PALOMA A. BARROS, , CAIO C. SANTOS, \\ VIVIANE A. ESCÓCIO, ${ }^{* *}$ MARCIA CHRISTINA A. M. LEITE, \\ ANA MARIA F. DE SOUSA* and MARCOS V. COLAÇO ${ }^{* * *}$

\begin{abstract}
*Chemical Institute, Rio de Janeiro State University, 524 São Francisco Xavier Str., Pavilhão Haroldo Lisboa da Cunha, 310, Maracanã, 20550-900, Rio de Janeiro, RJ, Brazil

*Instituto de Macromoléculas Professora Eloisa Mano, Rio de Janeiro Federal University, 2013 Horário Macedo Avenue, BL J, Cidade Universitária, 21941-598, Rio de Janeiro, RJ, Brazil

${ }^{* * *}$ Physics Institute, Rio de Janeiro State University, 524 São Francisco Xavier Str., BL B, Maracanã, 20550-900, Rio de Janeiro, RJ, Brazil

× Corresponding author: A. M. Furtado de Sousa, ana.furtado.sousa@gmail.com
\end{abstract}

Received May 18, 2020

\begin{abstract}
The present works describes the effect produced by mechanical disc refining in the pretreatment of lignocellulose agroindustrial waste, using scraps of sponge gourd. Two batches of sponge gourd scraps were refined in a laboratory disc refiner, at a consistence of $2.9 \mathrm{wt} \%$ (fiber/water) and residence time of 2 and $4 \mathrm{~min}$. The two batches were then coded as MRS and HRS, respectively. MRS and HRS samples, as well as non-refined sponge gourd (NRS), were characterized in terms of morphological aspects, structural characteristics and thermal behavior. The analysis of SEM micrographs revealed that internal fibrillation dominated the refining process of sponge gourd, which, consequently, led to an increased surface area of the fibers. It was observed that the use of the disc refiner promoted the extraction of some hemicellulose content, increased the devolatilization index to $70 \%$ and $60 \%$, as well as crystallinity - to $22 \%$ and $31 \%$ for MRS and HRS, respectively.
\end{abstract}

Keywords: sponge gourd, lignocellulose fibers, mechanical disc refiner, morphology, thermal behavior, crystallinity index

\section{INTRODUCTION}

Lignocellulosic biomass comprises byproducts of agricultural crops and industrial waste, and has attracted considerable attention due to its vast potential to produce many valuable products. This fibrous residue is composed of cellulose, hemicelluloses, lignin, and other minor components. Because of its complex composition, the lignocellulosic residue should be subjected to a series of pretreatments so as to separate its main constituents, enabling to produce biocomposites, biofuels, biochemicals and catalysts. ${ }^{1-3}$

Traditionally, the pretreatments of lignocellulosic fibers can be classified into physical, chemical, physicochemical, biological, and their combination. ${ }^{4}$ Generally, physical pretreatment contributes to reducing the size, increasing the surface area and accessibility of the fibers, and reducing the crystallinity of cellulose. ${ }^{4}$

${ }^{6}$ Physical pretreatment comprises mechanical comminution, irradiation, extrusion, and pulsed electric energy processes, but most of them are only used at a laboratory scale..$^{3-4,6-7}$

Refining or beating is a mechanical process used in cellulose and paper industries with the purpose of producing significant changes in the cellulose fiber, such as: swelling caused by external and internal fibrillation, fines formation, shortening and straightening. Further, changes in cellulose crystallinity and rearrangement of surface chemical components are characteristics that can also be affected by mechanical refining. In this process, cellulose fibers are modified by the action of compressive and shear tensions during the movement of an aqueous suspension of fibers between, at least, two parallel grooved discs (stator and rotor). ${ }^{5,8}$ There are several types of refiners for industrial purposes, however, the most modern disc refiners show many advantages, such 
as lower energy consumption and cost, and the possibility to be used with higher pulp consistency. ${ }^{9}$ Regarding the refiner for laboratory scale, the most common types are PFI (manufactured by Norwegian Pulp \& Paper Research Institute), Jokro mills, Valley beater, and disc refining. ${ }^{8,10}$

Although, the benefits obtained from using the refining process in the pulp and paper industry are generally recognized, there are only a few studies in the literature regarding the use of this process for pretreatment of lignocellulosic residue, PFI refiners being the most frequently used ones. Chen et $a l .{ }^{11}$ presented a study about the effect of several physical treatments (food processor blender, laboratory disc refiner, PFI mill, and corotating twin-screw extruder) on the improvement of enzymatic digestion yield, applied to chemically pretreated corn stover. According to the authors, the best results were achieved by PFI mill and twin-screw extruder refining, showing a yield improvement of $16-20 \%$. Ertas et al. ${ }^{12}$ reported an increase in the enzymatic hydrolysis yield by applying the PFI refiner to wheat straw previously hydrolyzed at $180{ }^{\circ} \mathrm{C}$, for $20 \mathrm{~min}$ and at $4 \mathrm{FPU} / \mathrm{g}$ enzyme dosage (FPU is filter paper unit, and 1 FPU is defined as enzyme amount that is needed to release $2 \mathrm{mg}$ of reducing sugars from $50 \mathrm{mg}$ of Whatman No. 1 filter paper as a substrate). Similar findings were reported by $\mathrm{Xu}$ et $a l .{ }^{13}$ for corn stover using a PFI refiner. Recently, Cheng et al. ${ }^{14}$ stated that using the mechanical disc refiner to process sorghum bagasse (previously hydrothermally pretreated at $160-190{ }^{\circ} \mathrm{C}$ for $10 \mathrm{~min}$ ) enhanced the yield of glucose and xylose production, as compared to the use of hydrothermal pretreatment alone.

Luffa cylindrica is an interesting waste as a source of lignocellulosic raw material, because this vegetable is composed of approximately 60 $\mathrm{wt} \%$ of cellulose, $30 \mathrm{wt} \%$ of hemicelluloses and $10 \mathrm{wt} \%$ of lignin. ${ }^{15-16}$ It is a member of the Cucurbitaceae family, very abundant in tropical and subtropical countries, and it is commonly known as sponge gourd. Although Luffa cylindrica can be edible like summer squash, if it is harvested before internal fibers have started to harden, it is more recognized for its uses as personal hygiene products and for making handicrafts, ${ }^{16-17}$ generating a considerable amount of waste. Recently, Adewuyi and Pereira, ${ }^{18}$ Zaafouri et al. ${ }^{19}$ and Verma et al. ${ }^{17}$ conducted interesting studies using sponge gourd as raw material to produce, respectively, adsorbents, bioethanol, and cellulase. However, these research works have only focused on using chemical processes to pretreat the sponge gourd.

In the light of the aspects discussed above, the aim of our work was to propose a physical process, including a step of mechanical refining, to pretreat sponge gourd scraps. Thus, in order to understand the benefits generated for the process proposal, non-refined and refined sponge gourd samples were characterized with respect to fiber morphology, physical characteristics and thermal behavior, and the results obtained were intensely discussed so as to map possible uses for this valuable material.

\section{EXPERIMENTAL \\ Materials}

Luffa cylindrica or sponge gourd (SG) scraps were donated by Co-op, localized in Bonfim City, Minas Gerais, Brazil. Sodium hydroxide was donated by Teadit.

\section{Lignocellulosic raw material pretreatment}

Since the sponge gourd (SG) received is an agroindustrial waste, it was expected that it may contain foreign materials. Thus, the first step of the process was to inspect visually the batch in order to remove any contaminants present. Then, the batch of SG was milled using a hammer mill (100 HP, $1700 \mathrm{RPM})$ and then screened using a Tyler sieve (mesh 20). A sample was taken at this stage and coded as NRS (non-refined sample) to be use as reference. Thereafter, $0.4 \mathrm{~kg}$ of SG was added to a vessel that contained $14 \mathrm{~L}$ of water and $5.6 \mathrm{~g}$ of $\mathrm{NaOH}\left(0.01 \mathrm{~mol}^{-1} \mathrm{~L}^{-1}\right)$. The aqueous suspension of lignocellulose fiber (consistence: $2.9 \%$ ) was allowed to rest for 12 hours, and then, it was submitted to a refining process in a laboratory disc refiner (Regmed MD-300). The refining process parameters were set as follows: mass consistence at $2.9 \%$, disc gap of $0.095 \mathrm{~mm}$, amperage ranging from 14 to 17 A. Further, two residence times were used: 2 and 4 minutes. The codification used for the refined lignocellulose fibers was: MRS (medium refined sample - residence time $2 \mathrm{~min}$ ) and HRS (highly refined sample - residence time $4 \mathrm{~min}$ ). After the refining step, both refined lignocellulose fiber batches (MRS and HRS) were filtered, washed, dried in an air circulating oven at $50{ }^{\circ} \mathrm{C}$ for 40 hours, and screened manually using a Tyler sieve (mesh 20). Figure 1 illustrates the flow diagram of the physical pretreatment process.

\section{Characterization Morphological analysis}

The morphology of NRS, MRS and HRS samples was analyzed in a JEOL JSM-6510LV microscope, 
with SEI detector. The samples were gold coated after being fixed on a metal stub with carbon tape.

\section{Bulk density}

The bulk density is the ratio of the mass to the volume, including the contribution of the interparticle void volume. The procedure used was: $100 \mathrm{~g}$ of each sample (NRS, MRS and HRS) was introduced carefully (without compacting) into a dry graduated cylinder $(250 \mathrm{~mL})$. The surface of the samples was carefully leveled and then the unsettled apparent volume was read. The bulk density $\left(\mathrm{g} \cdot \mathrm{mL}^{-1}\right)$ was determined by dividing the mass $(100 \mathrm{~g})$ by the apparent volume. The tests were performed in triplicate.

\section{Fourier-transform infrared spectroscopy (FTIR)}

FTIR spectra of the samples were obtained using a PerkinElmer Frontier FTIR/FIR spectrometer, in the attenuated total reflectance (ATR) mode. The range of the scanning was $4000-600 \mathrm{~cm}^{-1}, 32$ scans were taken, with a resolution of $4 \mathrm{~cm}^{-1}$. The peaks were determined using the PerkinElmer Spectrum software. All spectra were baseline corrected and reported in absorbance. The tests were performed in triplicate.

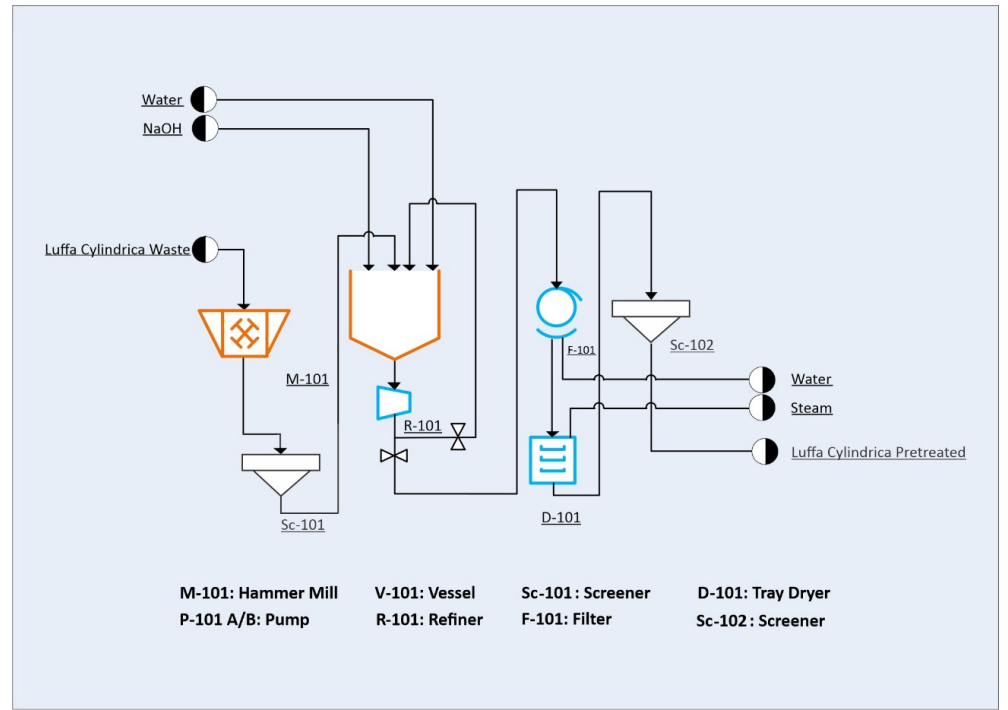

Figure 1: Flow diagram of physical pretreatment process of Luffa cylindrica agro-industrial waste as raw material

\section{Thermogravimetric analysis (TGA)}

Thermal degradation of NRS, MRS and HRS was investigated in a Q50 series thermogravimetric analyzer, from TA Instruments, using sample amounts of about $5 \mathrm{mg}$, the scanning temperature from 50 to $600{ }^{\circ} \mathrm{C}$, a heating rate of $20{ }^{\circ} \mathrm{C} \cdot \mathrm{min}^{-1}$ under nitrogen atmosphere. The tests were performed in triplicate.

\section{$X$-ray diffraction (XRD)}

The lignocellulose samples were analyzed using a Bruker-AXS D8 Advance Eco diffractometer with a $\mathrm{Cu} \mathrm{k} \alpha(\lambda=1.54180 \AA)$ source. The voltage and current used were $40 \mathrm{kV}$ and $25 \mathrm{~mA}$, respectively. The $2 \theta$ range was defined from $5^{\circ}$ and $65^{\circ}$ in the BraggBrentano geometry, with a 0.01 step size and scan time.

\section{RESULTS AND DISCUSSION Morphological analysis and bulk density measurement}

The morphology of NRS, MRS and HRS is shown in Figure 2. It is observed that NRS consists of bundles of fibers, which are bonded together by hemicelluloses and lignin (Fig. 2a-b). The fiber of NRS is intact (Fig. 2 (a)), its outer surface layer is smooth and homogeneous (Fig. 1 (b)), although it has been submitted to milling (M-101, Fig. 1) and screening (Sc-101, Fig. 1) processes. Furthermore, no impurities are observed on the NRS surface.

After the mechanical refining, the intact fiber of sponge gourd does not exist anymore, and interesting changes in fiber morphology are observed. As mentioned in the literature regarding the mechanical refining process, ${ }^{8-9}$ external fibrillation occurs due to the peeling off of fibrils from the fiber surface, while internal fibrillation is characterized by the delamination of the fiber's internal walls. This last type of fibrillation is generated by the action of compressive forces that breaks the inner bonds between cellulosic fibrils, cellulosic fibrils-hemicelluloses, cellulose-lignin, 
and hemicelluloses-lignin, producing internal porosity, and as a consequence, swelling by water penetration. Therefore, the morphologies observed in Figure 2 for the MRS and HRS samples, compared to NRS, probably indicate that internal fibrillation dominated the refining process, favoring the delamination, and consequently, separating fibers into their inner layers. Consequently, the bundles of microfibril aggregates have been loosened and then released, this effect being more noticeable for HRS (Fig. 2 (c-d)). The MRS and HRS fibers appear to be more flexible than NRS, indicating that it is a characteristic produced by internal fibrillation. ${ }^{8-9}$ Furthermore, both MRS and HRS show a certain degree of heterogeneity regarding the size of the fibers, as well as the presence of fragments caused by fiber shortening. This fiber morphology change produced by mechanical refining is valuable, since it allowed increasing the available surface area, which was indirectly confirmed by the bulk density measurement. Thus, bulk density values of 220,130 and $120 \mathrm{~kg} . \mathrm{m}^{-3}$ were obtained for, respectively, NRS, MRS and HRS, revealing a reduction of approximately $40 \%$. Both morphology and bulk changes obtained for the lignocellulose fibers by using mechanical refining seem to be interesting since the higher surface area and flexibility contribute to increasing the efficiency of the thermochemical and biological conversion processes to be performed. Besides, the higher surface area is also interesting because it is a way to increase the interaction area between fibers and several types of matrices in biocomposite production.

\section{Fourier-transform infrared spectroscopy}

FTIR was used to identify the functional groups of cellulose, hemicelluloses and lignin present in the sponge gourd before and after being refined. The comparison among the ATR-FTIR spectra of NRS, MRS and HSR is illustrated in Figure 3 (a). The region $1800-600 \mathrm{~cm}^{-1}$, where the most relevant vibration bands of cellulose, hemicelluloses and lignin are located, is shown in Figure 3 (b).
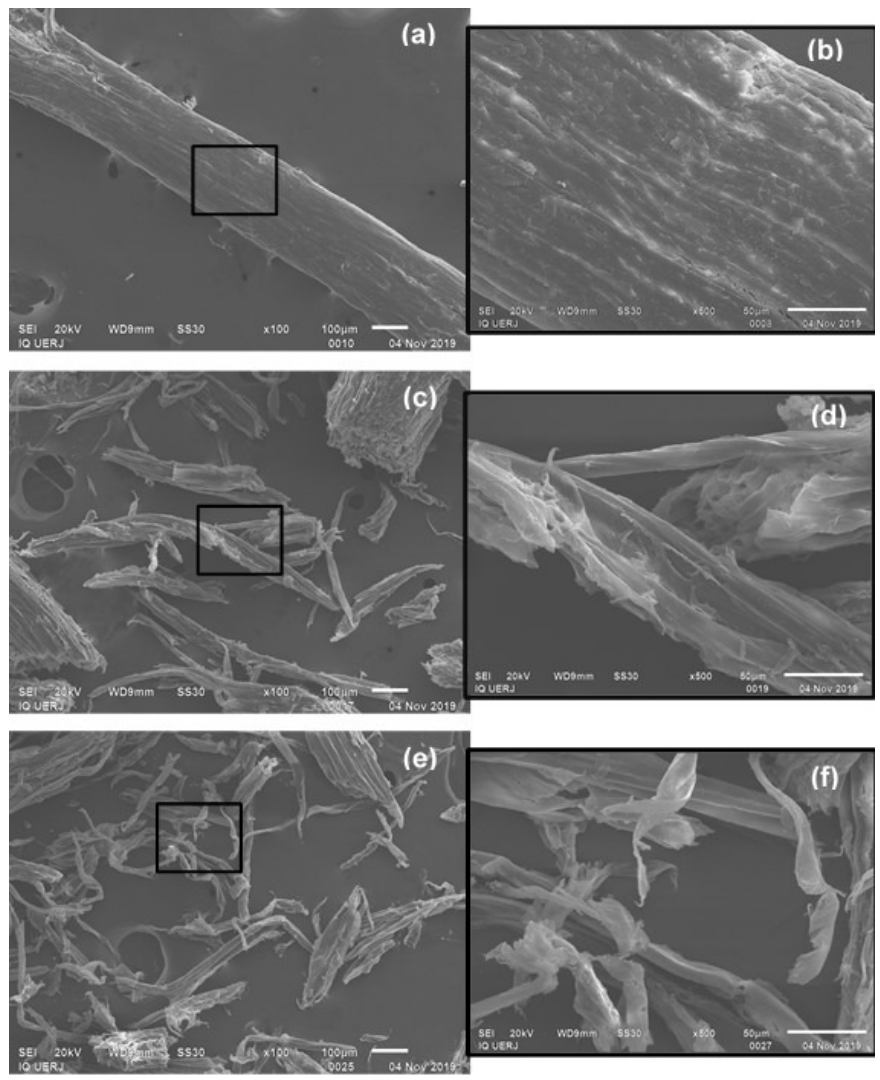

Figure 2: SEM photomicrographs of lignocellulose fiber samples: NRS (a-b), MRS (c-d) and HRS (e-f) 

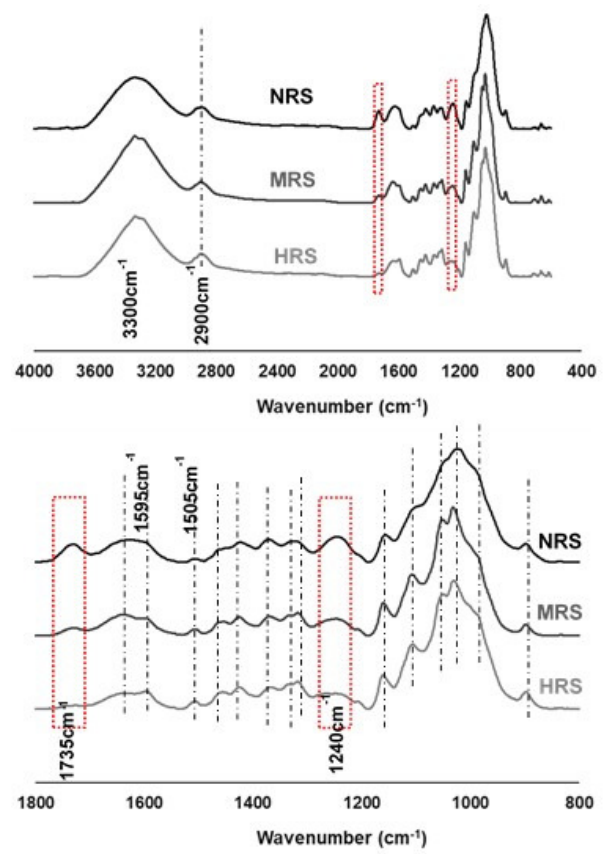

Figure 3: ATR-FTIR spectra of NRS, MRS, HRS in the range of $4000-600 \mathrm{~cm}^{-1}$ and $1800-600 \mathrm{~cm}^{-1}$
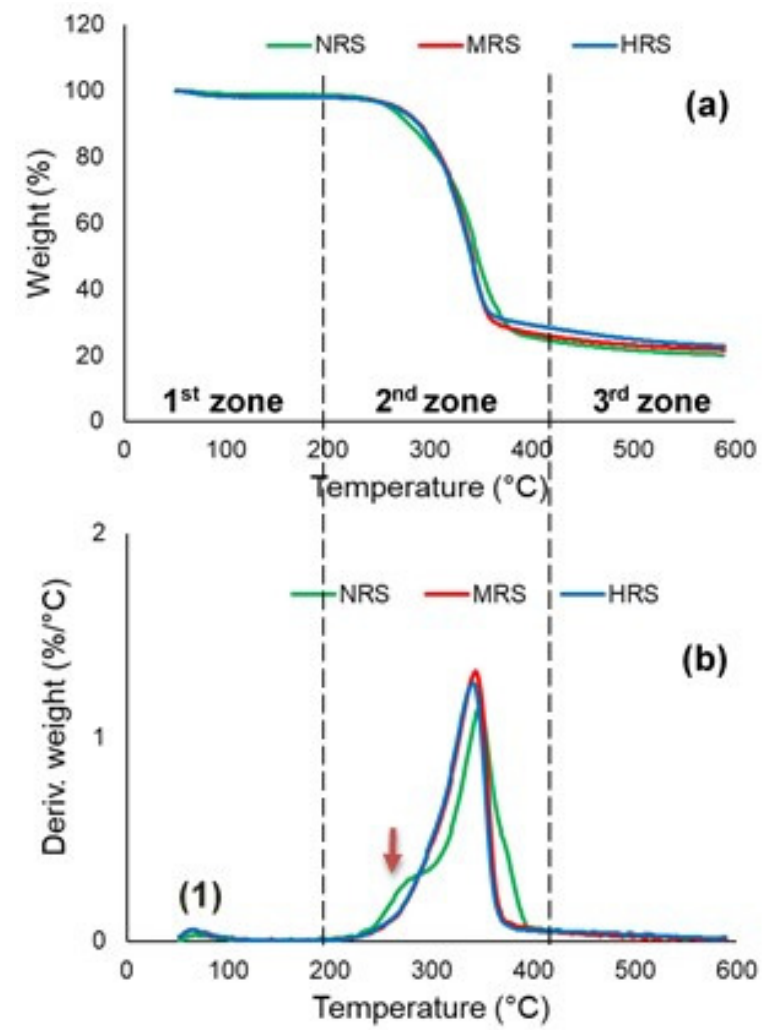

Figure 4: TGA (a) and DTG (b) curves of NRS, MRS, HRS samples

Generally, no significant difference is observed among the spectra, except for the decrease of the intensity bands located in the regions between $1728-1736 \mathrm{~cm}^{-1}$ and $1220-1270$ $\mathrm{cm}^{-1}$ (Fig. 3 (b)). This behavior was not expected, since the disc refining process is mechanical, and 
even though sodium hydroxide $(\mathrm{NaOH})$ had been used, its amount was very small $(0.04 \mathrm{wt} \%)$, as well as the residence time used in the refining (2 and 4 minutes). The band around $1735 \mathrm{~cm}^{-1}$ can be assigned to the stretching vibrations of carboxyl and acetyl groups present in hemicelluloses, pectin and waxes. ${ }^{20-23}$ The weak band at $1240 \mathrm{~cm}^{-1}$ is attributed to the aromatic ring vibration of lignin, ${ }^{20,22-23}$ and $\mathrm{C}-\mathrm{O}-\mathrm{C}$ stretching of ether linkage of hemicelluloses. ${ }^{20}$ Considering the fact that there is no reduction in the intensity of other characteristic bands of lignin, for instance those at 1505 and $1595 \mathrm{~cm}^{-1}$, $20-$ ${ }_{23}$ it is possible that some content of hemicelluloses has been extracted from sponge gourd during mechanical refining.

\section{Thermogravimetric analysis}

Figure 4 shows the comparison of weight loss (TGA) and the first derivative of weight loss (DTG) curves for NRS, MRS and HRS as a function of temperature. As stated in the literature ${ }^{24}$ the TGA thermogram can be divided into three regions. The first one $\left(\sim 25-200{ }^{\circ} \mathrm{C}\right)$, considered as dry region, is characterized by the moisture loss and light volatile material release. The second region $\left(\sim 200-500{ }^{\circ} \mathrm{C}\right)$ is where the active pyrolysis of the lignocellulose materials happens, and it is characterized by a large amount of volatile release. Finally, the third one ( $500-$ $1000{ }^{\circ} \mathrm{C}$ ) is named passive pyrolysis, and it is described by a prolonged tailing, no peaks, and a slow rate of degradation, which is mostly ascribed to the final reaction of lignin degradation and any carbonaceous matter decomposition.

Table 1 shows the temperatures in which the active pyrolysis of sponge gourd starts $\left(\mathrm{T}_{\text {onset }}\right)$ and ended $\left(T_{\text {endset }}\right)$, as well as the temperature at the maximum degradation rate $\left(T_{\max }\right)$, determined from the TGA/DTG curves. A small weigh loss is observed around $100{ }^{\circ} \mathrm{C}$ (peak 1 in DTG, Fig. 4 (a)), related to the release of moisture present in the sponge gourd, with values of $1.6 \pm 0.5,1.7 \pm$ 0.3 , and $1.7 \pm 0.3 \mathrm{wt} \%$ determined for NRS, MRS and HRS, respectively.

Table 1

Thermal properties of NRS, MRS and HRS (average values of triplicate tests)

\begin{tabular}{lccccc}
\hline Sample & $\begin{array}{c}\mathrm{T}_{\text {onset }} \\
\left({ }^{\circ} \mathrm{C}\right)\end{array}$ & $\begin{array}{c}\mathrm{T}_{\max } \\
\left({ }^{\circ} \mathrm{C}\right)\end{array}$ & $\begin{array}{c}\mathrm{T}_{\text {endset }} \\
\left({ }^{\circ} \mathrm{C}\right)\end{array}$ & $\begin{array}{c}(d w / d t)_{\max } \\
(\% / \min )\end{array}$ & $\begin{array}{c}\mathrm{D}_{\mathrm{i}} \\
\left(10^{-6} \% \cdot \min ^{-1}{ }^{\circ} \mathrm{C}^{-3}\right)\end{array}$ \\
\hline NRS & $241 \pm 2$ & $347 \pm 0$ & $389 \pm 2$ & $18.5 \pm 0.5$ & $4.0 \pm 0.1$ \\
MRS & $265 \pm 2$ & $344 \pm 0$ & $364 \pm 0$ & $27.0 \pm 0.5$ & $6.9 \pm 0.1$ \\
HRS & $269 \pm 1$ & $341 \pm 0$ & $362 \pm 0$ & $26.0 \pm 0.5$ & $6.4 \pm 0.1$ \\
\hline
\end{tabular}

Above $200{ }^{\circ} \mathrm{C}$, there is a main peak in DTG (Fig. 4 (b)) related to the pyrolysis of hemicelluloses, cellulose and lignin. It is generally accepted that the pyrolysis of hemicelluloses and cellulose occurs at $220-315{ }^{\circ} \mathrm{C}$ and $315-400{ }^{\circ} \mathrm{C}$, respectively, giving their maximum degradation rates around 250-300 and $355{ }^{\circ} \mathrm{C} .{ }^{25-26}$ Different from hemicelluloses and cellulose, the degradation of lignin happens under a wide range of temperature. Zhang et al. ${ }^{19}$ studied the thermal degradation of three types of lignin (prairie cordgrass, aspen and kraft) by TGA-FTIR and concluded that some lignin contains volatiles that can be released at 30-200 ${ }^{\circ} \mathrm{C}$. Furthermore, the authors reported that lignin decomposition occurs at $200-500{ }^{\circ} \mathrm{C}$, with the maximum degradation rates in the range of 330$390{ }^{\circ} \mathrm{C}$. It is observed in Figure 4 (b) that NRS shows a different DTG curve pattern from NRS and HRS, that is, the main degradation peak of
NRS has a shoulder at $296 \pm 2{ }^{\circ} \mathrm{C}$ (see arrow in Figure 4 (b)), which is ascribed to hemicelluloses degradation, although some content of lignin may also have undergone thermal decomposition. ${ }^{27}$ The absence of the shoulder in the DTG curves of MRS and HRS corroborates to the fact that hemicelluloses were extracted from MRS and HRS during mechanical refining, as verified by FTIR. In fact, the presence of this shoulder can be considered as the reason why NRS presented lower $\mathrm{T}_{\text {onset }}$ than MRS and HRS (Table 1).

In addition, the values of $T_{\max }$ (Table 1) of MRS and HRS were lower than the value of NRS. This is an interesting result since the removal of hemicelluloses should have contributed to an increase in $\mathrm{T}_{\max }$, not the opposite. Another result important to highlight is the lower values of $\mathrm{T}_{\text {endset }}$ (around $-25{ }^{\circ} \mathrm{C}$ ) of MRS and HRS, compared to the value of NRS. The reduction of $T_{\max }$ and $\mathrm{T}_{\text {endset }}$ of both MRS and HRS fibers happened 
because these two refined fibers have higher accessible surface area than NRS (see above), therefore the heat and mass transfer is facilitated, as compared to the NRS process. In an attempt to measure the difference among the samples regarding the main degradation event, the devolatilization index, $D_{i}$, was calculated using Equation (1). ${ }^{28}$

$D i=(d w / d t)_{\max } /\left(\mathrm{T}_{\max } \mathrm{T}_{\text {in }} \Delta \mathrm{T}_{1 / 2}\right)$

where $(d w / d t)_{\max }$ is the maximum degradation rate, $T_{i n}$ is the initial devolatilization temperature, $T_{\max }$ is the maximum mass loss temperature, and $\Delta T_{1 / 2}$ is the temperature range at $(d w / d t) /(d w / d t)_{\max }$ equal to $1 / 2 .^{28}$ As shown in Table 1, based on the fact that the $D_{i}$ values of MRS and HRS are higher than that of NRS, one can infer that the mechanical refining process makes lignocellulose fibers become more thermally reactive. Furthermore, no difference in the results was observed with respect to the residence time used during refining.

\section{X-ray diffraction}

The diffractograms of NRS, MRS and HRS were analyzed by the structural Rietveld refinement method, which is pointed out by some authors as one of the most advanced methods for fitting crystalline cellulose peaks to the experimental data. ${ }^{29-30}$ At first, in order to quantify the background, aluminum oxide $\left(\mathrm{Al}_{2} \mathrm{O}_{3}\right)$ standard and NRS, MRS and HRS were measured under the same experimental conditions. The background and instrumental broadening parameters of the standard were fitted and kept fixed for subsequent refinements. The amorphous contribution was modeled by means of a Pawley fit.

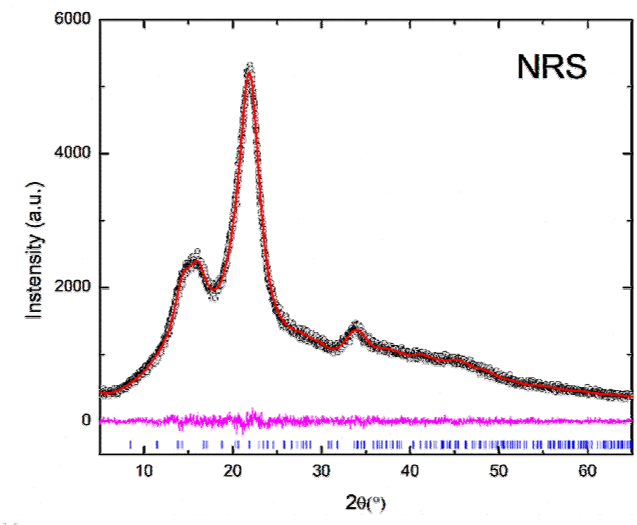

a)

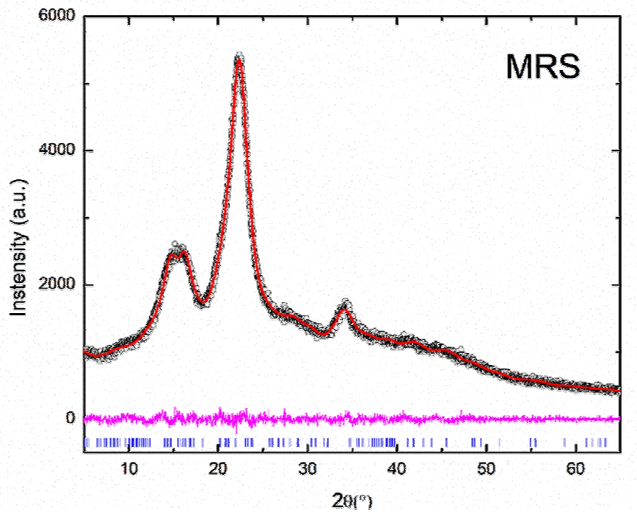

b)

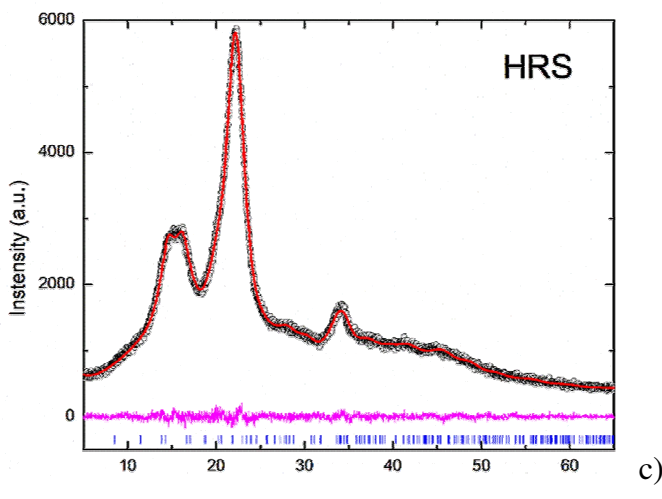

Figure 5: Rietveld graphs (the red curve is the calculated pattern and black open circles are the experimental data) of (a) NRS, (b) MRS and (c) HRS with cellulose phase I $\beta$ (blue tick marks) and difference between experimental and calculated profile (pink curve)

The values of the space group and cell parameters used to start the structure refinement were obtained using the CSD code JINROO01(I $\beta)$, with $\mathrm{a} / \mathrm{b} / \mathrm{c}$ parameters of
7.784(8)/8.201(8)/10.380(10) for cellulose $\mathrm{I} \beta .^{30}$ The refined parameters used were: scale factor, unit cell, sample displacement, crystallite size and, as known, the fibers present an orientation 
and, for this reason, spherical harmonic preferred orientation was refined to adjust the intensities. ${ }^{32}$ Figure 5 shows the Rietveld refinement of NRS, MRS and HRS. The quality parameter related to the Rietveld refinement were as follows: (a) NRS: $\mathrm{R}_{\mathrm{wp}}: 3.04 \%$, $\mathrm{R}_{\text {bragg: }}: 0.12 \%$, GoF: 1.07 ; (b) MRS: $\mathrm{R}_{\mathrm{wp}}: 2.99 \%$, $\mathrm{R}_{\text {bragg }}: 0.17 \%$, GoF: 1.11 , (c) HRS: $\mathrm{R}_{\mathrm{wp}}: 2.98 \%, \mathrm{R}_{\text {bragg }}: 0.47 \%$, GoF: 1.10 .

The crystallinity index (CrI) of the sponge gourd samples determined from the Rietveld refinement curves wa calculated dividing the area of the crystalline contribution by the total area (sum of crystalline and amorphous contributions), thus values of $44.8 \%, 54.5 \%$ and $58.5 \%$ were obtained for the NRS, MRS and HRS samples, respectively. It means that the crystallinity of the amount of cellulose present in the material rose after mechanical disc refining. There are two factors that can explain this finding: the first one is the extraction of a certain amount of the amorphous components from the lignocellulose material, that is, the hemicelluloses removal, as discussed above. Indeed, the increase in $\mathrm{CrI}$ observed corroborates the statement regarding the extraction of hemicelluloses during refining. The second reason is the low residence time ( 2 and 4 minutes) of refining used in this work. This hypothesis was considered since it is well recognized in the literature that the crystallinity of cellulose can be increased during the initial phase of mechanical refining, but it is reduced as the residence time is prolonged. ${ }^{8}$ The increase in the $\mathrm{CrI}$ of sponge gourd produced by mechanical refining can be of interest when considering the possible use of the material as reinforcement in biocomposites, since the crystallinity of cellulose is directly related to the mechanical properties of the fiber. ${ }^{29}$

\section{CONCLUSION}

The sponge gourd waste underwent severe transformations after it was subjected to mechanical disc refining as pretreatment. The morphological analysis showed that the original shape of the non-refined sponge gourd, NRS, changed significantly, from an intact fiber to the condition where the inner layers of the fiber were exposed after mechanical refining. As a result, the accessible surface and flexibility of MRS and HRS rose, and their bulk density reduced in comparison with that of the non-refined sample, NRS. Both morphology and bulk changes produced in the sponge gourd fibers by the refining process seem to be interesting since higher surface area and flexibility contribute to increasing the efficiency of further thermochemical and biological conversion processes, as well as improving the interaction between fibers and several types of matrix in biocomposite production. Furthermore, both FTIR and thermal analyses showed that hemicelluloses were extracted from MRS and HRS during mechanical disc refining. Additionally, it was verified that mechanical disc refining contributes to increasing the thermal reactivity of MRS and HRS, as compared to NRS. This result can be interesting for the thermal conversion application of lignocellulosic materials. Lastly, the X-ray diffraction analysis showed that mechanical disc refining contributes to increasing the crystallinity of lignocellulose samples. This increase in crystallinity was attributed to the hemicellulose removal from the material and to the low residence times used in the refining process. Thus, it can be concluded that the use of mechanical disc refining as physical pretreatment for sponge gourd agro-industrial waste has a great potential to produce lignocellulose fibers with unique and attractive properties for several applications, such as biocomposite and biofuel production.

ACKNOWLEDGEMENTS: The authors thank Teadit for performing the mechanical disc refining, as well as Conselho Nacional de Desenvolvimento Científico e Tecnológico CNPQ (30617/2018-00), Fundação de Amparo à Pesquisa do Estado do Rio de Janeiro - FAPERJ (E-26/010.002212/2019 and E26/010.001927/2019), and Coordenação de Aperfeiçoamento de Pessoal de Nível Superior CAPES (Financing code 001) for supporting the present research.

\section{REFERENCES}

1 A. Algieri, S. Andiloro, V. Tamburino and D. A. Zema, Renew. Sust. Energ. Rev., 104, 1 (2019), https://doi.org/10.1016/j.rser.2019.01.001

2 N. M. Huzir, M. M. A. Aziz, S. B. Ismail, B. Abdullah, N. A. N. Mahmood et al., Renew. Sust. Energ. Rev., 94, 476 (2018), https://doi.org/10.1016/j.rser.2018.06.036

3 S. Paul and A. Dutta, Resour. Conserv. Recycl., 130 164 (2018),

https://doi.org/10.1016/j.resconrec.2017.12.005

4 P. Halder, S. Kundu, S. Patel, A. Setiawan, R. Atkin et al., Renew. Sust. Energ. Rev., 105, 268 (2019), https://doi.org/10.1016/j.rser.2019.01.052 
5 J. Chen, K. Adjallé, S. Barnabé, M. Perrier and J. Paris, Waste Biomass Valorif., 10, 2057 (2019), https://doi.org/10.1007/s12649-018-0217-X

6 S. Q. Tian, R. Y. Zhao and Z. C. Chent, Renew. Sust. Energ. Rev., 91, 483 (2018), https://doi.org/10.1016/j.rser.2018.03.113

7 B. Kumar, N. Bhardwaj, K. Agrawal, V. Chaturvedi and P. Verma, Fuel Process. Technol., 199, 106244 (2020), https://doi.org/10.1016/j.fuproc.2019.106244

S. Gharehkhani, E. Sadeghinezhad, S. N. Kazi, H. Yarmand, A. Badarudin et al., Carbohyd. Polym., 115, 785 (2015), https://doi.org/10.1016/j.carbpol.2014.08.047

9 J. Park, B. Jones, B. Koo, X. Chen, M. Tucker et al., Bioresour. Technol., 199, 59 (2016), https://doi.org/10.1016/j.biortech.2015.08.059

10 B. W. Jones, R. Venditti, S. Park and H. Jameel, BioResources, 12, $4567 \quad$ (2017), https://ojs.cnr.ncsu.edu/index.php/BioRes/article/view/ BioRes_12_3_4567_Jones_Pilot_Scale_Mechanical_D isk_Refining

11 X. Chen, E. Kuhn, W. Wang, S. Park and K. Flanegan, Bioresour. Technol., 147, 401 (2013), https://doi.org/10.1016/j.biortech.2013.07.109

12 M. Ertas, Q. Han, H. Jameel and H.-M. Chang, Bioresour. Technol., 152, 259 (2014), https://doi.org/10.1016/j.biortech.2013.11.026

13 H. Xu, B. Li, X. Mu, G. Yu, C. Liu et al., Bioresour. Technol., 169, $19 \quad$ (2014), https://doi.org/10.1016/j.biortech.2014.06.068

14 M. H. Cheng, B. S. Dien, D. K. Lee and V. Singh, Bioresour. Technol., 121, 663 (2019), https://doi.org/10.1016/j.biortech.2019.121663

15 H. A. N Cong, J. H. Zuo, W. A. N. G. Qing, H. Z. Dong and L. P. Gao, J. Integr. Agric., 16, 735 (2017), https://doi.org/10.1016/S2095-3119(16)61390-4

16 A. Saeed and M. Iqbal, Biotechnol. Prog., 29, 573 (2013), https://doi.org/10.1002/btpr.1702

17 N. Verma, V. Kumar and M. C. Bansal, Biocatal. Agric. Biotechnol., 16, $483 \quad$ (2018), https://doi.org/10.1016/j.bcab.2018.09.021

18 A. Adewuyi and F. V. Pereira, J. Assoc. Arab Univ. Basic Appl. Sci., 24, 39 (2017), https://doi.org/10.1016/j.jaubas.2016.12.003

19 M. Zhang, F. L. Resende, A. Moutsoglou and D. E. Raynie, J. Anal. Appl. Pyrol., 98, 65 (2012), https://doi.org/10.1016/j.jaap.2012.05.009
20 A. Boukir, S. Fellak and P. Doumenq, Heliyon, 5, e02477

(2019), https://doi.org/10.1016/j.heliyon.2019.e02477

21 D. Dai and M. Fan, Vib. Spec., 55, 300 (2011), https://doi.org/10.1016/j.vibspec.2010.12.009

22 F. Xu, J. Yu, T. Tesso, F. Dowell and D. Wang, Appl. Energ., 104, $801 \quad$ (2013), https://doi.org/10.1016/j.apenergy.2012.12.019

${ }^{23}$ R. Kempaiah, G. Gurappa, R. Tomar, M. Poletto, H. L. O. Junior et al., Cellulose Chem. Technol., 54, 187 (2020) https://doi.org/10.35812/CelluloseChemTechnol.2020. 54.21

24 S. El-Sayed, Eng. Agric. Environ. Food, 12, 460 (2019), https://doi.org/10.1016/j.eaef.2019.08.002

25 F. Nsaful, F. X. Collard, M. Carrier, J. F. Görgens and J. H. Knoetze, J. Anal. Appl. Pyrol., 116, 86 (2015), https://doi.org/10.1016/j.jaap.2015.10.002

26 H. Yang, R. Yan, H. Chen, D. H. Lee and C. Zheng, Fuel, 86, $1781 \quad$ (2007), https://doi.org/10.1016/j.fuel.2006.12.013

27 Z. Chen, M. Hu, X. Zhu, D. Guo, S. Liu et al., Bioresour. Technol., 192, 441 (2015), https://doi.org/10.1016/j.biortech.2015.05.062

${ }_{28}$ Z. Wu, S. Wang, J. Zhao, L. Chen and H. Meng, Bioresour. Technol., 169, $220 \quad$ (2014), https://doi.org/10.1016/j.biortech.2014.06.105

29 P. Ahvenainen, I. Kontro and K. Svedström, $\begin{array}{llll}\text { Cellulose, } & \text { 23, } & 1073 & \text { (2016), }\end{array}$ https://doi.org/10.1007/s10570-016-0881-6

30 Z. Ling, T. Wang, M. Makarem, M. S. Cintrón, H. N. Cheng et al., Cellulose, 26, 305 (2019), https://doi.org/10.1007/s10570-018-02230-x

31 Y. Nishiyama, P. Langan and H. Chanzy, J. Am. Chem. Soc., 124, $9074 \quad$ (2002), https://doi.org/10.1021/ja0257319

32 M. Järvinen, J. Appl. Cryst., 26, 525 (1993), https://doi.org/10.1107/S0021889893001219 